\title{
Clinicopathological characteristics of malignant melanomas of the skin and gastrointestinal tract
}

\author{
MICHIKO AKIYAMA $^{1,2}$, YOKO MATSUDA ${ }^{2}$, TOMIO ARAI ${ }^{2}$ and HIDEHISA SAEKI ${ }^{1}$ \\ ${ }^{1}$ Department of Dermatology, Nippon Medical School, Tokyo 113-8603; ${ }^{2}$ Department of Pathology, \\ Tokyo Metropolitan Geriatric Hospital, Tokyo 173-0015, Japan
}

Received October 12, 2017; Accepted May 3, 2018

DOI: $10.3892 / \mathrm{ol} .2018 .8913$

\begin{abstract}
The present study examined the differences between gastrointestinal melanoma (GM) and skin melanoma (SM). The clinicopathological characteristics, the expression of melanoma stem cell markers nestin, sex determining region Y-box 2 and ATP-binding cassette sub-family B member 5, and the presence of the $B R A F^{V 600 E}$ mutation were evaluated in 10 cases of GM and 31 cases of SM. Patients with GM had an increased mean age compared with those with SM (76 vs. 68 years). In addition, GMs were significantly more likely than SMs to be amelanotic (50 vs. 7\%; $\mathrm{P}=0.001)$ and display round cells ( 70 vs. $23 \% ; \mathrm{P}=0.02$ ). The mitosis rate was also significantly higher in GM compared with SM $(\mathrm{P}<0.05)$. The incidence of lymph-node metastasis (60 vs. 32\%; $\mathrm{P}<0.05$ ) and distant metastasis (10 vs. $6.5 \%, \mathrm{P}=0.02)$ was significantly higher in GMs compared with SMs. The expression of stem cell markers did not differ significantly between groups, however, in the SM group advanced-stage disease was associated with a significantly higher expression of nestin than early-stage disease $(\mathrm{P}<0.05)$. Immunohistochemically, the expression of $\mathrm{BRAF}^{\mathrm{V} 600 \mathrm{E}}$ was significantly lower in GMs compared with in SMs (1.0 vs. $3.3 ; \mathrm{P}=0.01)$. These findings indicate that the identification of these features may aid in the diagnosis of GM and SM, as well as contribute to the development of novel targeted therapies against GM.
\end{abstract}

\section{Introduction}

The incidence of malignant melanoma is increasing worldwide; approximately 160,000 cases were diagnosed in 2002 (1), and 232,000 in $2012(2,3)$. Melanoma is one of the most aggressive tumors, and the survival time of melanoma patients with distant metastasis is only between 9 (4) and 18 (5) months.

Correspondence to: Dr Michiko Akiyama, Department of Dermatology, Nippon Medical School, 1-1-5 Sendagi, Bunkyo-ku, Tokyo 113-8603, Japan

E-mail: michiko02@nms.ac.jp

Key words: gastrointestinal melanoma, malignant melanoma, $B R A F^{V 600 E}$, mitosis, nestin, stem cell marker
Melanomas are most commonly localized in the skin but can arise anywhere in the body where melanocytes exist (6). During early embryogenesis, melanoblasts migrate from the neural crest to various sites, including the mucosal surfaces of the body (e.g., lining the sinuses, nasal passages, oral cavity, vagina, and anus), and these can transform into cancerous cells, resulting in mucosal melanoma (7). Mucosal melanoma is a rare form of this disease, making up only about $1.2 \%$ of white, non-Hispanic cases in the United States (8) and 3\% of Japanese cases $(9,10)$.

Anorectal lesions are the most common type of mucosal melanomas, followed by those of the eye, oral-nasopharynx, and esophagus (11-13). Gastrointestinal melanoma (GM), a malignant melanoma arising in the gastrointestinal tract, is a major type of mucosal melanoma. However, there have been many debates as to its true origin, e.g., the gut vs. a distant, undetected primary lesion that has regressed, known as melanoma of unknown primary.

Cancer stem cells (CSCs) are tumor cells with stem cell properties. The concept of the melanoma stem cell was first reported in 2005 (14). Melanoma stem cells are thought to have self-renewal ability, multilineage potential (15), and resistance to chemotherapy $(16,17)$. Several markers have been reported to be melanoma stem cell markers, such as nestin (18), SOX2 (19), and ABCB5 (20).

The clinicopathological characteristics of melanoma are drastically different with respect to primary site and tumor stage. The prognosis for mucosal melanoma is extremely poor compared to that for skin melanoma (SM), and the 5-year survival rate associated with SM is $81 \%$ but that associated with mucosal melanoma is only $25 \%$ (8) SM has been clinicopathologically categorized into four types according to Clark's classification (21): i) lentigo maligna; ii) superficial spreading; iii) acral lentiginous; and iv) nodular. Recently, Bastian et al (22) proposed a new classification for SM that considers sun exposure and gene abnormalities $(22,23)$. This became a major classification with the advances in molecular targeted therapy for melanomas with a $B R A F$ mutation (24). However, there are no universal staging systems for GM (25). GM is difficult to diagnose at an early stage because of the anatomical location of the disease. It is usually challenging for pathologists to diagnose GM, especially given the small amount of biopsy samples usually collected. Previous studies have indicated GMs with BRAF and NRAS mutations are 
significantly rare (23), whereas activating KIT mutations have been reported in $>30 \%$ of case $(24,26)$ and also $N F 1$ mutations have been found in $20 \%$ of anorectal melanoma cases (27). However, the clinicopathological characteristics of GM have not been well clarified. In this report, we attempt to determine the clinicopathological differences between GM and SM.

Surgical resection is the first choice of treatment for early-stage melanoma (Stages I and II), whereas treatment for Stages III and IV melanomas with lymph-node and/or distant metastasis has been evolving dramatically along with the development of novel targeted therapies and immunotherapies. Moreover, metastatic melanoma patients with the $B R A F$ mutations are commonly treated with dabrafenib or vemurafenib (28). Therefore, accurate diagnosis of GM is essential for implementing appropriate therapeutic plans.

In the present study, we investigated the clinicopathological characteristics of and presence of the $B R A F^{V 600 E}$ mutation in GM patients, and compared these findings to those of SM patients.

\section{Materials and methods}

Patients and tissues. Tissue samples [GM (n=10) and SM $(n=31)]$ were obtained from patients who had undergone surgical treatment at our hospital from 1997 to 2015. This study was conducted in accordance with the principles embodied in the Declaration of Helsinki (2008). Approval for the study was obtained from the Human Research Ethics Committees at the Tokyo Metropolitan Geriatric Hospital (no. R17-33) and the Nippon Medical School Hospital (no. 29-07-805); written informed consent was obtained from all patients.

Tissue processing and histological assessment. Tissues were fixed in formalin and subjected to standard processing and paraffin embedding. They were sliced into $3-\mu \mathrm{m}$ thick sections for hematoxylin and eosin (H\&E) staining and immunohistochemical analysis. Diagnoses of pathological specimens were made by more than two pathologists based on the American Joint Committee on Cancer (AJCC, 2009) guidelines for SMs and the Union for International Cancer Control (UICC, 7th edition) guidelines for GMs.

Analyses of immunohistochemistry and mitosis findings. Paraffin-embedded tissue sections were immunostained using Histofine Simple Stain MAX PO (Nichirei, Tokyo, Japan) kits. After deparaffinization, endogenous peroxidase activity was blocked by incubating sections with $0.3 \%$ hydrogen peroxide in methanol for $30 \mathrm{~min}$. Sections were incubated in either the absence (negative control) or presence of a monoclonal anti-nestin antibody (diluted 1:100, incubated for $1 \mathrm{~h}$ at room temperature; MAB5326; EMD Millipore, Billerica, MA, USA), anti-ABCB5 antibody (diluted 1:160, incubated for $1 \mathrm{~h}$ at room temperature; SAB1300315; Sigma-Aldrich; Merck KGaA, Darmstadt, Germany), anti-SOX2 antibody (diluted 1:800, incubated for $1 \mathrm{~h}$ at room temperature; GT15098; Neuromics, Edina, MN, USA), anti-BRAF V600E antibody (diluted 1:50, incubated overnight at $4^{\circ} \mathrm{C}$; E19290; Spring Bioscience, Pleasanton, CA, USA), and anti-MIB-1 antibody (diluted 1:100, incubated for $30 \mathrm{~min}$ at room temperature; M7240; Dako; Agilent Technologies, Inc., Santa Clara, CA,
USA). Bound antibodies were detected using diaminobenzidine tetrahydrochloride as a chromogen. Immunohistochemical review was performed separately by two of the authors, who were blinded to clinical and outcome data. For the evaluation of immunostaining, intensity and area of the positive tumor cells were determined separately, based upon scores of 0-3+. Intensity was scored as follows: 0 , negative; $1+$, low; $2+$, intermediate, and $3+$, high. Area was scored as follows: $0,<25 ; 1+$, $25-50 ; 2+, 50-75 ; 3+,>75 \%$. Tissue magnification was $\mathrm{x} 200$. Intensity and area scores were then multiplied for statistical analysis.

We used representative $H \& E$-stained slides to count the number of normal mitoses and atypical mitoses at $\mathrm{x} 400$ magnification. Atypical mitosis was defined as anything other than the typical form of normal mitosis, for example, asymmetrical, ring, and multipolar mitoses. The total mitosis count included atypical and normal mitoses. For statistical analysis, we averaged the value of the findings from the two authors who provided immunohistochemical reviews.

DNA Extraction, polymerase chain reaction (PCR). DNA was extracted from $10 \%$ formalin-fixed, paraffin-embedded tissues using the TaKaRa DEXPAT ${ }^{\mathrm{Tm}}$ kit (Takara Bio, Inc., Otsu, Japan), according to the manufacturer's instructions.

A $B R A F^{V 600 E}$ mutation was analyzed in the total volume of the PCR mixture $(20 \mu \mathrm{l})$, which contained the following: $10 \mu 1$ of $\operatorname{TaqMan}^{\circledR}$ Genotyping Master mix (Thermo Fisher Scientific, Inc., Waltham, MA, USA), $4 \mu \mathrm{l}$ of prepared gDNA sample, $4 \mu \mathrm{l}$ of nuclease-free water, and $2 \mu \mathrm{l}$ of TaqMan ${ }^{\circledR}$ Mutation Detection Assay (Thermo Fisher Scientific, Inc.), according to the manufacturer's instructions (29). This mixture contains an allele-specific probe to identify the presence of p.V600E substitution in a BRAF gene. Amplification of the examined region was performed in 96-well plates as follows: pre-denaturation at $95^{\circ} \mathrm{C}$ for $10 \mathrm{~min} ; 5$ cycles each at $92^{\circ} \mathrm{C}(12 \mathrm{sec} /$ cycle $)$ and $58^{\circ} \mathrm{C}(60 \mathrm{sec} /$ cycle $) ; 40$ cycles at $92^{\circ} \mathrm{C}(15 \mathrm{sec} /$ cycle $)$ and at $60^{\circ} \mathrm{C}(60 \mathrm{sec} /$ cycle $)$. Each sample was sequenced by Quant Studio ${ }^{\circledR} 5$ Real-Time PCR system (Thermo Fisher Scientific, Inc.).

Statistical analysis. Clinicopathological features were analyzed by using Chi-square test and Student's t-test. The level of significance was set at $\mathrm{P}<0.05$ for all analyses. Statistical analyses were performed using the StatViewJ version 5.0 software package (SAS Institute, Inc., Cary, NC, USA).

\section{Results}

The clinicopathological characteristics of patients with SM and GM are shown in Table I. As no specific inclusion/exclusion criteria were set, we analyzed all patients reviewed for this study. The SM patient group comprised 17 men and 14 women with a mean range in age of 66.7 (24-87) years. The GM patient group comprised 5 men and 5 women with a mean range in age of 75.7 (40-94) years. The mean age of the GM patients was higher than that of the SM patients; however, the difference was not statistically significant.

T4 SM of the back shows an elevated nodule on the epithelium (Fig. 1A). Malignant melanoma of the rectum shows a thickened glandular epithelium with tumor cell invasion (Fig. 1B). 
Table I. Clinicopathological characteristics of SM and GM.

\begin{tabular}{|c|c|c|}
\hline Characteristic & SM & GM \\
\hline Age $($ mean \pm SD) & $66.7 \pm 16.8$ & $75.7 \pm 14.9$ \\
\hline \multicolumn{3}{|l|}{ Gender, n (\%) } \\
\hline Male & $17(54.8)$ & $5(50.0)$ \\
\hline Female & $14(45.2)$ & $5(50.0)$ \\
\hline \multicolumn{3}{|l|}{ Location, n (\%) } \\
\hline Acral & $13(41.9)$ & - \\
\hline CSD & $4(12.9)$ & - \\
\hline Mucosal & $2(6.5)$ & - \\
\hline Non-CSD & $12(38.7)$ & - \\
\hline Oesophagus & - & $1(10.0)$ \\
\hline Rectum & - & $4(40.0)$ \\
\hline Anal canal & - & $4(40.0)$ \\
\hline Small intestine & - & $1(10.0)$ \\
\hline \multicolumn{3}{|c|}{ Cell morphology, n (\%) } \\
\hline Spindle & $24(77.4)^{\mathrm{a}}$ & $3(30.0)$ \\
\hline Round & $7(22.6)$ & $7(70.0)$ \\
\hline \multicolumn{3}{|l|}{ Melanin, n (\%) } \\
\hline Negative & $2(6.5)^{\mathrm{a}}$ & $5(50.0)$ \\
\hline Positive & $29(93.5)$ & $5(50.0)$ \\
\hline \multicolumn{3}{|c|}{ T-classification, n (\%) } \\
\hline 1 & $8(25.8)$ & $3(30.0)$ \\
\hline 2 & $11(35.5)$ & $0(0.0)$ \\
\hline 3 & $11(35.5)$ & $5(50.0)$ \\
\hline 4 & $1(3.2)$ & $2(20.0)$ \\
\hline \multicolumn{3}{|c|}{ N-lymph node, n (\%) } \\
\hline Negative & $21(67.7)$ & $4(40.0)$ \\
\hline Positive & $10(32.3)^{\mathrm{a}}$ & $6(60.0)$ \\
\hline \multicolumn{3}{|l|}{ M-metastasis, n (\%) } \\
\hline Negative & $30(96.8)$ & $8(80.0)$ \\
\hline Positive & $1(3.2)^{\mathrm{a}}$ & $2(20.0)$ \\
\hline \multicolumn{3}{|l|}{ UICC stage, n (\%) } \\
\hline $\mathrm{I}$ & $8(25.8)$ & $3(30.0)$ \\
\hline II & $11(35.5)$ & $0(0.0)$ \\
\hline III & $11(35.5)$ & $5(50.0)$ \\
\hline IV & $1(3.2)$ & $2(20.0)$ \\
\hline
\end{tabular}

The data are presented as the mean \pm standard deviation, or $\mathrm{n}(\%)$. A melanoma case of small intestine had history of thymic melanoma. ${ }^{\mathrm{a}}<0.05$ vs. gastrointestinal tract by Chi-square test. SM, skin melanoma; GM, gastrointestinal melanoma; CSD, chronic sun damage.

Findings of melanoma in situ (Fig. 1C, SM) or of junctional components (Fig. 1D, GM) adjacent to the invasive tumor was considered evidence for identifying a lesion as primary rather than metastatic. Melanin deposition in melanoma cells (Fig. 1E) and around tumor cells (Fig. 1F) are shown.

The morphological characteristics of SMs (Fig. 2A) and GMs (Fig. 2B) show that GMs were more likely to display round cells (Fig. 2B) than were SMs (Fig. 2A) (70 vs. 23\%, $\mathrm{P}=0.02)$. Furthermore, GM lesions were more likely to be amelanotic (Fig. 2B) than were SMs (Fig. 2C) (50 vs. 7\%, $\mathrm{P}=0.001)$. The incidence of lymph-node metastasis was significantly higher in GMs than in SMs (60 vs. 32\%, P<0.04), and distant metastases were more likely to be detected in GMs ( 10 vs. $6.5 \%, \mathrm{P}=0.02)$ at the point of resection. The percentage of UICC stage IV patients in GMs was higher than that of AJCC stage IV patients in SMs (30 vs. 3.2\%, $\mathrm{P}=0.03$ ).

Mitosis rates and MIB-1 labeling indices are shown in Table II. The MIB-1 indices tended to be higher in GMs than in SMs; however, the difference was not statistically significant. The rate of mitoses was significantly higher in GMs (Fig. 2D) than in SMs (35.8 vs. 14.5, $\mathrm{P}=0.02$ ), whereas the difference in number of atypical mitoses was not statistically significant. 


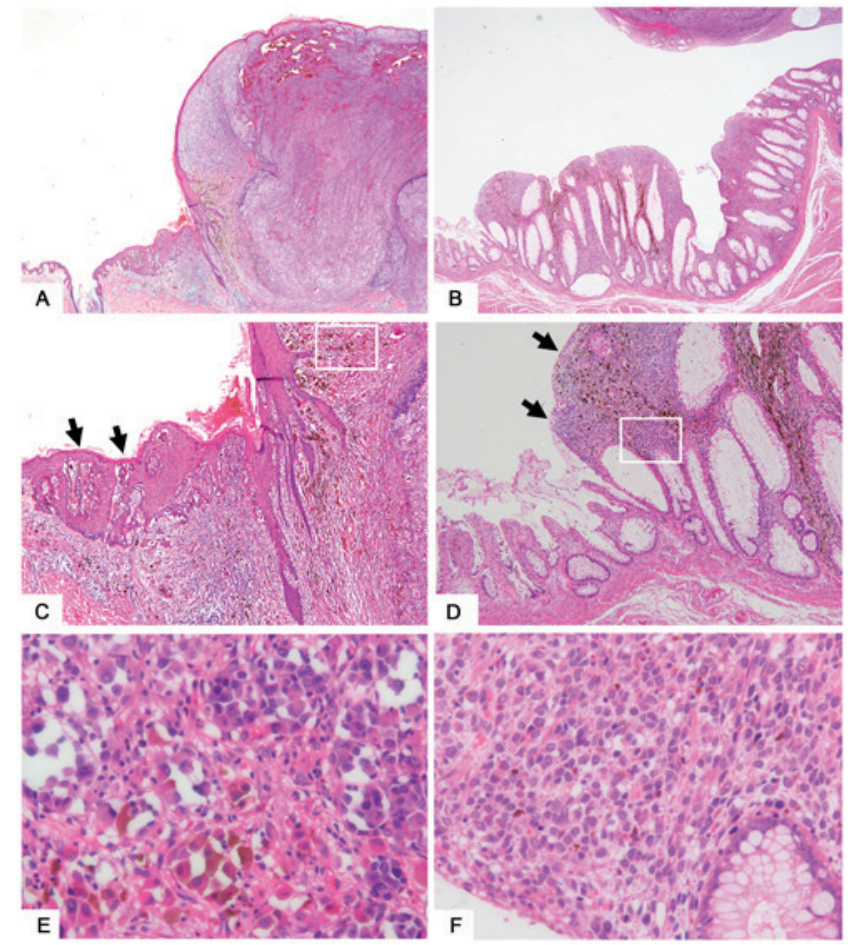

Figure 1. Representative features of skin and gastrointestinal melanomas. (A) T4 skin melanoma tissue sample taken from the back. Magnification, x20 (B) Malignant melanoma of the rectum. Magnification, x20. (C) Melanoma in situ (arrow) seen adjacent to the nodular lesion of skin melanoma. Magnification, x100. (D) Melanoma cells (arrow) seen in the mucosal layer adjacent to the elevated lesion of gastrointestinal melanoma. Magnification, x100. (E) Magnification of a squared area of part (C). Melanoma cells showing hyperchromatic nuclei with melanin deposition in the cytoplasm. Magnification, x400. (F) Magnification of a squared area of part (D). Magnification, $\mathrm{x} 400$.
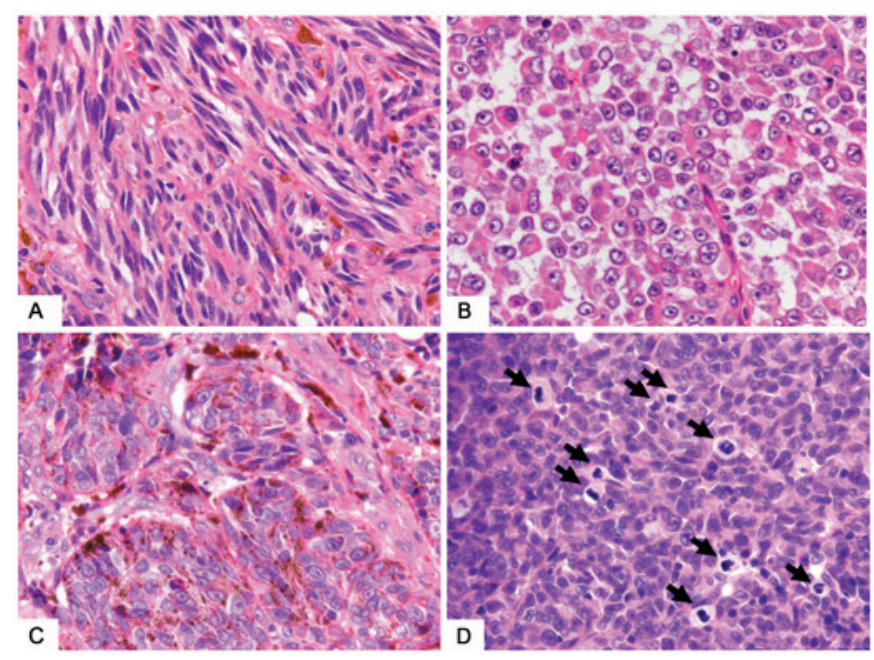

Figure 2. Morphological characteristics of gastrointestinal and skin melanomas. (A) SM showing spindle-shaped tumor cells. (B) GM showing round or epithelioid shapes and amelanotic tumor cells. (C) Melanin deposition in SM tumor cells. (D) Major normal mitosis (arrow) seen in GM. Magnification, x600. SM, skin melanoma; GM, gastrointestinal melanoma.

Next, we compared advanced melanoma (Stage III and IV) to early melanoma (Stage I and II) (Table II). Results for Stage III and IV GMs were significantly higher than those for Stage I and II GMs with respect to normal mitosis (2.7 vs. 37.5,
Table II. MIB-1 indices and mitoses.

\begin{tabular}{lcc}
\hline Indices & SM & GM \\
\hline MIB-1 index & $25.6 \pm 19.1$ & $35.0 \pm 18.1$ \\
Stage I-II & $22.2 \pm 17.2$ & $21.7 \pm 10.4$ \\
Stage III-IV & $30.8 \pm 21.5$ & $40.7 \pm 18.1$ \\
Normal mitosis & $10.6 \pm 15.8$ & $27.1 \pm 24.7^{\mathrm{a}}$ \\
Stage I-II & $6.5 \pm 9.6$ & $2.7 \pm 2.3$ \\
Stage III-IV & $17.1 \pm 21.4$ & $37.5 \pm 22.1^{\mathrm{b}}$ \\
Atypical mitosis & $3.9 \pm 7.5$ & $8.7 \pm 7.8$ \\
Stage I-II & $2.1 \pm 3.3$ & $1.2 \pm 0.9$ \\
Stage III-IV & $6.6 \pm 11.0$ & $11.9 \pm 2.6^{\mathrm{b}}$ \\
Total mitosis & $14.5 \pm 22.7$ & $35.8 \pm 30.7^{\mathrm{a}}$ \\
Stage I-II & $8.6 \pm 12.8$ & $3.8 \pm 3.5$ \\
Stage III-IV & $23.8 \pm 31.3$ & $49.4 \pm 26.2^{\mathrm{b}}$
\end{tabular}

Data are presented as the mean \pm standard deviation. ${ }^{\text {a }} \mathrm{P}<0.05$ vs. SM by Student's t-test. ${ }^{\text {P }}<0.05$ vs. stage I-II by Student's t-test. SM, skin melanoma; GM, gastrointestinal melanoma.

$\mathrm{P}=0.03)$, atypical mitosis (1.2 vs. $11.9, \mathrm{P}=0.03)$ and total mitosis (3.8 vs. $49.4, \mathrm{P}=0.02$ ). The rate of mitoses in Stage III and IV SMs tended to be higher than that in Sage I, II; however, the difference was not statistically significant.

Expression levels of stem cell markers nestin, ABCB5, and SOX2 were similar between GMs and SMs (Table III). Stage III and IV SMs and GMs were associated with higher expression of these markers than were Stage I and II SMs and GMs. Only nestin expression was statistically significantly higher in Stage III, IV SMs (Fig. 3A) than in Stage I and II SMs (9.6 vs. 6.3, $\mathrm{P}=0.02$; Fig. 3B).

We used PCR to examine $B R A F^{V 600 E}$ mutations. Mutations were positive in 6 cases (all SMs) and negative in 15 cases (12 SMs and 3 GMs). The remaining 20 cases (13 SM and 7 GM) were not evaluated because the samples were old and small in quantity. Immunohistochemically, the expression of $\mathrm{BRAF}^{\mathrm{V} 600 \mathrm{E}}$ was lower in GMs (Fig. 3C) than in SMs (Fig. 3D and Table III) (1.0 vs. $3.3, \mathrm{P}=0.01)$. Cases with the $B R A F^{V 600 E}$ mutation showed higher expression of the BRAF ${ }^{V 600 E}$ protein than did cases without the mutation (6.7 vs. $1.9, \mathrm{P}=0.002$ ) (Table IV).

\section{Discussion}

Our investigation revealed that, compared with SM patients, patients with GMs were generally older and more likely to display round cells and to be amelanotic. Moreover, they had a higher incidence of lymph-node and distant metastases, were more often in an advanced stage of the disease at the point of resection, and had a lower frequency of $B R A F^{V 600 E}$ mutations than did SM patients. In our analysis, we found the peak age at diagnosis to be in the 60s for SMs and 70s for GMs, which is consist with a previous report (8).

Melanoma tumor cells vary greatly in size, shape, and morphological characteristics. Epithelioid and spindle-shaped cells are two major SM-cell types. Generally, lentigo maligna and acral lentiginous types tend to show a 
Table III. Score of positive cells of immunohistochemical markers.

\begin{tabular}{lcc}
\hline Marker & SM & GM \\
\hline Nestin & $7.6 \pm 3.9$ & $6.7 \pm 2.8$ \\
Stage I-II & $6.3 \pm 3.9$ & $5.7 \pm 2.5$ \\
Stage III-IV & $9.6 \pm 2.9^{\mathrm{b}}$ & $7.1 \pm 3.0$ \\
ABCB5 & $1.3 \pm 0.6$ & $1.2 \pm 0.6$ \\
Stage I-II & $1.2 \pm 0.6$ & $1.0 \pm 0.0$ \\
Stage III-IV & $1.4 \pm 0.7$ & $1.3 \pm 0.8$ \\
SOX2 & $0.9 \pm 1.3$ & $0.8 \pm 1.4$ \\
Stage I-II & $3.0 \pm 3.9$ & $1.5 \pm 0.5$ \\
Stage III-IV & $2.3 \pm 2.0$ & $5.5 \pm 5.0$ \\
BRAF & $3.3 \pm 3.3$ & $1.0 \pm 1.5^{\mathrm{a}}$ \\
Stage I-II & $2.9 \pm 3.2$ & $1.0 \pm 1.0$ \\
Stage III-IV & $4.1 \pm 3.3$ & $1.0 \pm 1.2$ \\
\hline
\end{tabular}

The data represent the mean \pm standard deviation. ${ }^{a} \mathrm{P}<0.05$ vs. SM by Student's t-test. ${ }^{b} \mathrm{P}<0.05$ vs. stage I-II by Student's t-test. SM, skin melanoma; GM, gastrointestinal melanoma.

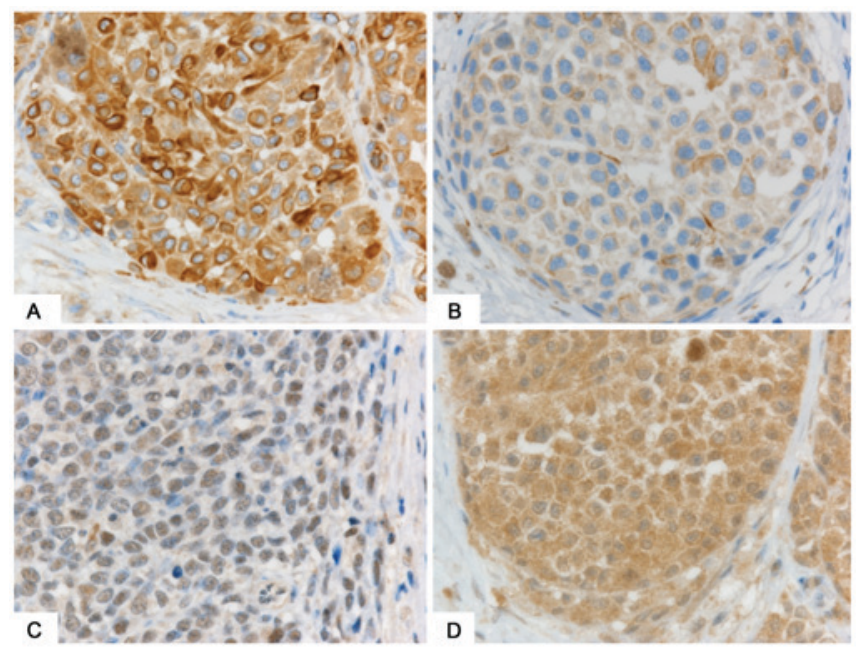

Figure 3. Immunohistochemical staining for nestin and $B R A F^{V 600 E}$. (A) Stage IV SM showing strong expression of nestin. (B) Stage II SM showing weak expression of nestin. (C) Absence of immunoreactivity to BRAF in gastrointestinal melanoma. (D) Strong expression of BRAF in SM. Counterstaining was by hematoxylin. Magnification, x600. SM, skin melanoma.

predominance of spindle-shaped cells among their invasive dermal components, whereas superficial-spreading and nodular lesions tend to be composed largely of epithelioid cells (30). In previous reports, approximately $70 \%$ of anorectal melanomas showed an epithelioid phenotype $(27,31)$, which is consistent with our study results. Amelanotic melanoma was found in 50\% of GMs in our study, as opposed to $21 \%$ in a previous report concerning anorectal melanoma (31), suggesting a higher incidence of amelanotic features in GMs than in SMs.

Cell proliferation is one of the major characteristics of malignant tumors. Numerous studies have shown that mitotic
Table IV. Results of BRAF mutation by polymerase chain reaction and immunohistochemistry.

\begin{tabular}{lcc}
\hline Type & $\begin{array}{c}B R A F^{V 600 E} \\
\text { mutation } \\
\text { by PCR }\end{array}$ & $\begin{array}{c}\text { Immunohistochemical } \\
\text { score of BRAF } \\
\text { expression }\end{array}$ \\
\hline Wild type & 15 & $1.9 \pm 2.8$ \\
Mutant type & 6 & $6.7 \pm 1.6^{\mathrm{a}}$ \\
N.D. & 20 & - \\
\hline
\end{tabular}

${ }^{a} \mathrm{P}<0.005$ vs. wild type by chi square test. The data represent the number of cases and the mean score \pm standard deviation. N.D., not determined.

rate is associated with the prognosis for SM $(32,33)$. In the present study, the number of normal and total mitoses were found to be higher in GM, than in SM, suggesting that GM might be more aggressive than SM, thereby resulting in GM's poorer prognosis. However, the MIB-1 index did not show a significant difference between GM and SM. We believe that this lack of a MIB-1 index difference has a few possible explanations. First, the mitosis number was counted by the hot spot area, whereas the MIB-1 index was evaluated by the entire region on the slide. Furthermore, the mitosis number included abnormal mitoses, which may count alterations related to chromosomal abnormalities. Finally, the MIB-1 index considers all cells except those in the G0 phase of the cell cycle. These disparities between mitosis and the MIB-1 index may have influenced our results.

Previous studies have suggested that melanoma stem cells play important roles in cell proliferation as well as in tumor initiation, development, recurrence, and resistance to chemotherapy $(15,17)$. SRY (sex-determining region Y)-box (SOX2) is a transcription factor expressed by neural progenitor cells that also regulates the nestin core enhancer (19). Recent reports have shown that SOX-2 contributes to cell invasion (34), while regulating the self-renewal ability and tumorigenicity of human melanoma-initiating cells (35). ABCB5 is a members of the ATP-binding cassette (ABC) superfamily of transporters and is targeted in chemotherapeutic drug-efflux pumps (20). Immunostaining of ABCB5 has been shown to have higher expression in invasive than in in situ melanoma, suggesting that it is a key player in the development of melanoma (36). Various types of stem cell markers have been identified for SM, while little is known about stem cell markers for GM. We found expression levels of nestin, ABCB5, and SOX2 to be similar in GM and SM, suggesting that these stem cell marker-related proteins might play similar roles in both diseases. However, nestin expression was higher in advanced stages of SM than in early stages. Nestin is an intermediate filament protein that regulates cell proliferation via cyclin-dependent kinases and AKT (37). Similarly, it has been reported that nestin plays important roles in cell proliferation and metastasis of melanoma (18,38-40). Taken together, these findings suggest that nestin plays important roles in melanoma stem cells, and has potential as a novel targeted therapy. 
We confirmed a low frequency of $B R A F^{V 600 E}$ mutation in GMs as compared with that in SMs. A recent meta-analysis showed that immunohistochemistry is highly sensitive and specific for the detection of the $B R A F^{V 600 E}$ mutation and highly comparable to genetic methodology in melanoma cases (41). Findings of a few analyses have indicated that $B R A F$ and NRAS mutations in GM are exceedingly rare (23), whereas activating KIT mutations are found in $>30 \%$ of cases $(24,26)$. The present study also found a high concordance between immunostaining and PCR in detecting $B R A F^{V 600 E}$. Therefore, immunohistochemical staining might be more useful than PCR, especially with a small number of biopsy samples.

Our study has several imitations. Primarily, the number of cases was small and most of the patients were elderly, especially for the GM group. However, our study might provide useful information for making differential diagnoses of GMs. Further study is needed to elucidate the mechanisms of GM's poor prognosis and to achieve early detection, thereby improving patient outcomes. In conclusion, we have identified differences in clinicopathological characteristics between GM and SM. In addition, we suggest a possible focus for a new molecular targeted treatment.

\section{Acknowledgements}

The authors would like to thank Dr. Seiichi Shinji (Surgery for Organ Function and Biological Regulation, Nippon Medical School, Tokyo, Japan) for his support in case presentations and Ms. Yasuko Hasegawa for her immunohistochemical work.

\section{Funding}

This work was supported by a Grant-in-Aid for Young Scientists (grant no. 15K19705).

\section{Availability of data and materials}

The datasets used and analyzed during the current study are available from the corresponding author on reasonable request.

\section{Authors' contributions}

MA, YM and TA conceived and designed the experiments. TA and $\mathrm{HS}$ contributed to the acquisition of data. MA selected the data and performed the experiments. MA and YM analyzed the data and wrote the paper. TA and HS critically revised the manuscript. All authors were involved in data interpretation and writing the manuscript, and have all read and approved the final version of the manuscript.

\section{Ethics approval and consent to participate}

The study was approved by the Human Research Ethics Committees at the Tokyo Metropolitan Geriatric Hospital (approval no. R17-33) and the Nippon Medical School Hospital (approval no. 29-07-805); written informed consent was obtained from all patients.

\section{Consent for publication}

Written informed consent was obtained from all patients.

\section{Competing interests}

The authors declare that they have no competing interests.

\section{References}

1. Parkin DM, Bray F, Ferlay J and Pisani P: Global cancer statistics, 2002. CA Cancer J Clin 55: 74-108, 2005.

2. Erdmann F, Lortet-Tieulent J, Schüz J, Zeeb H, Greinert R, Breitbart EW and Bray F: International trends in the incidence of malignant melanoma 1953-2008-are recent generations at higher or lower risk? Int J Cancer 132: 385-400, 2013.

3. Ferlay J, Soerjomataram I, Dikshit R, Eser S, Mathers C, Rebelo M, Parkin DM, Forman D and Bray F: Cancer incidence and mortality worldwide: Sources, methods and major patterns in GLOBOCAN 2012. Int J Cancer 136: E359-E586, 2015.

4. Lee ML, Tomsu K and Von Eschen KB: Duration of survival for disseminated malignant melanoma: Results of a meta-analysis. Melanoma Res 10: 81-92, 2000.

5. Balch CM, Gershenwald JE, Soong SJ, Thompson JF, Atkins MB, Byrd DR, Buzaid AC, Cochran AJ, Coit DG, Ding S, et al: Final version of 2009 AJCC melanoma staging and classification. J Clin Oncol 27: 6199-6206, 2009.

6. Baderca F, Vincze D, Balica N and Solovan C: Mucosal melanomas in the elderly: Challenging cases and review of the literature. Clin Interv Aging 9: 929-937, 2014.

7. Nordlund JJ: The lives of pigment cells. Clin Geriatr Med 5: 91-108, 1989.

8. Chang AE, Karnell LH and Menck HR: The National Cancer Data Base report on cutaneous and noncutaneous melanoma: A summary of 84,836 cases from the past decade. The American College of Surgeons Commission on Cancer and the American Cancer Society. Cancer 83: 1664-1678, 1998.

9. Umeda M, Mishima Y, Teranobu O, Nakanishi K and Shimada K: Heterogeneity of primary malignant melanomas in oral mucosa: An analysis of 43 cases in Japan. Pathology 20: 234-241, 1988

10. Fujisawa Y, Takahashi T, Yamamoto A, Yamazaki N, Saida T, Ishihara $\mathrm{K}$ and Ohtsuka: Statistics for malignant melanoma in Japan: A nationwide survey conductied during the calender years 2006 2007. Skin Cancer 23: 267-279, 2008.

11. Chen H, Cai Y, Liu Y, He J, Hu Y, Xiao Q, Hu W and Ding K: Incidence, surgical treatment, and prognosis of anorectal melanoma from 1973 to 2011: A population-based SEER analysis. Medicine (Baltimore) 95: e2770, 2016.

12. Arai T, Yanagisawa A, Kondo F, Aida $J$ and Takubo K: Clinicopathologic characteristics of esophageal primary malignant melanoma. Esophagus 13: 17-24, 2016.

13. Cheung MC, Perez EA, Molina MA, Jin X, Gutierrez JC, Franceschi D, Livingstone AS and Koniaris LG: Defining the role of surgery for primary gastrointestinal tract melanoma. J Gastrointest Surg 12: 731-738, 2008.

14. Fang D, Nguyen TK, Leishear K, Finko R, Kulp AN, Hotz S, Van Belle PA, Xu X, Elder DE and Herlyn M: A tumorigenic subpopulation with stem cell properties in melanomas. Cancer Res 65: 9328-9337, 2005

15. Reya T, Morrison SJ, Clarke MF and Weissman IL: Stem cells, cancer, and cancer stem cells. Nature 414: 105-111, 2001.

16. Schatton T, Murphy GF, Frank NY, Yamaura K, Waaga-Gasser AM, Gasser M, Zhan Q, Jordan S, Duncan LM, Weishaupt $\mathrm{C}$, et al: Identification of cells initiating human melanomas. Nature 451: 345-349, 2008.

17. Brinckerhoff CE: Cancer stem cells (CSCs) in melanoma: There's smoke, but is there fire? J Cell Physiol 232: 2674-2678, 2017.

18. Klein WM, Wu BP, Zhao S, Wu H, Klein-Szanto AJ and Tahan SR: Increased expression of stem cell markers in malignant melanoma. Mod Pathol 20: 102-107, 2007.

19. Tanaka S, Kamachi Y, Tanouchi A, Hamada H, Jing N and Kondoh H: Interplay of SOX and POU factors in regulation of the Nestin gene in neural primordial cells. Mol Cell Biol 24: 8834-8846, 2004. 
20. Frank NY, Margaryan A, Huang Y, Schatton T, Waaga-Gasser AM, Gasser M, Sayegh MH, Sadee W and Frank MH: ABCB5-mediated doxorubicin transport and chemoresistance in human malignant melanoma. Cancer Res 65: 4320-4333, 2005.

21. Clark WH Jr, From L, Bernardino EA and Mihm MC: The histogenesis and biologic behavior of primary human malignant melanomas of the skin. Cancer Res 29: 705-727, 1969.

22. Bastian BC, Olshen AB, LeBoit PE and Pinkel D: Classifying melanocytic tumors based on DNA copy number changes. Am J Pathol 163: 1765-1770, 2003.

23. Curtin JA, Busam K, Pinkel D and Bastian BC: Somatic activation of KIT in distinct subtypes of melanoma. J Clin Oncol 24 4340-4346, 2006

24. Curtin JA, Fridlyand J, Kageshita T, Patel HN, Busam KJ, Kutzner H, Cho KH, Aiba S, Bröcker EB, LeBoit PE, et al: Distinct sets of genetic alterations in melanoma. N Engl $\mathrm{J}$ Med 353: 2135-2147, 2005.

25. Edge SB and Compton CC: The American Joint Committee on Cancer: The 7th edition of the AJCC cancer staging manual and the future of TNM. Ann Surg Oncol 17: 1471-1474, 2010.

26. Santi R, Simi L, Fucci R, Paglierani M, Pepi M, Pinzani P, Merelli B, Santucci M, Botti G, Urso C and Massi D: KIT genetic alterations in anorectal melanomas. J Clin Pathol 68: 130-134, 2015.

27. Yang HM, Hsiao SJ, Schaeffer DF, Lai C, Remotti HE, Horst D, Mansukhani MM and Horst BA: Identification of recurrent mutational events in anorectal melanoma. Mod Pathol 30: 286-296, 2017.

28. Chapman PB, Hauschild A, Robert C, Haanen JB, Ascierto P, Larkin J, Dummer R, Garbe C, Testori A, Maio M, et al: Improved survival with vemurafenib in melanoma with BRAF V600E mutation. N Engl J Med 364: 2507-2516, 2011.

29. Richter A, Grieu F, Carrello A, Amanuel B, Namdarian K, Rynska A, Lucas A, Michael V, Bell A, Fox SB, et al: A multisite blinded study for the detection of BRAF mutations in formalin-fixed, paraffin-embedded malignant melanoma. Sci Rep 3: 1659, 2013

30. Clark WH Jr, Elder DE, Guerry D IV, Braitman LE, Trock BJ, Schultz D, Synnestvedt M and Halpern AC: Model predicting survival in stage I melanoma based on tumor progression. J Natl Cancer Inst 81: 1893-1904, 1989.

31. Tariq MU, Ud Din N, Ud Din NF, Fatima S and Ahmad Z: Malignant melanoma of anorectal region: A clinicopathologic study of 61 cases. Ann Diagn Pathol 18: 275-281, 2014.
32. Chu VH, Tetzlaff MT, Torres-Cabala CA, Prieto VG, Bassett R Jr, Gershenwald JE, McLemore MS, Ivan D, Wang WL, Ross MI and Curry JL: Impact of the 2009 (7th edition) AJCC melanoma staging system in the classification of thin cutaneous melanomas. Biomed Res Int 2013: 898719, 2013.

33. Mandalà M, Galli F, Cattaneo L, Merelli B, Rulli E, Ribero S, Quaglino P, De Giorgi V, Pigozzo J, Sileni VC, et al: Mitotic rate correlates with sentinel lymph node status and outcome in cutaneous melanoma greater than 1 millimeter in thickness: A multi-institutional study of 1524 cases. J Am Acad Dermatol 76: 264-73.e2, 2017.

34. Girouard SD, Laga AC, Mihm MC, Scolyer RA, Thompson JF, Zhan Q, Widlund HR, Lee CW and Murphy GF: SOX2 contributes to melanoma cell invasion. Lab Invest 92: 362-370, 2012.

35. Santini R, Pietrobono S, Pandolfi S, Montagnani V, D'Amico M, Penachioni JY, Vinci MC, Borgognoni L and Stecca B: SOX2 regulates self-renewal and tumorigenicity of human melanoma-initiating cells. Oncogene 33: 4697-4708, 2014.

36. Setia N, Abbas O, Sousa Y, Garb JL and Mahalingam M: Profiling of ABC transporters ABCB5, ABCF2 and nestin-positive stem cells in nevi, in situ and invasive melanoma. Mod Pathol 25: 1169-1175, 2012.

37. Matsuda Y, Ishiwata T, Yoshimura H, Yamahatsu K, Minamoto $\mathrm{T}$ and Arai T: Nestin phosphorylation at threonines 315 and 1299 correlates with proliferation and metastasis of human pancreatic cancer. Cancer Sci 108: 354-361, 2017.

38. Akiyama M, Matsuda Y, Ishiwata T, Naito Z and Kawana S: Nestin is highly expressed in advanced-stage melanomas and neurotized nevi. Oncol Rep 29: 1595-1599, 2013.

39. Ladstein RG, Bachmann IM, Straume O and Akslen LA: Nestin expression is associated with aggressive cutaneous melanoma of the nodular type. Mod Pathol 27: 396-401, 2014.

40. Akiyama M, Matsuda Y, Ishiwata T, Naito Z and Kawana S: Inhibition of the stem cell marker nestin reduces tumor growth and invasion of malignant melanoma. J Invest Dermatol 133: 1384-1387, 2013.

41. Anwar MA, Murad F, Dawson E, Abd Elmageed ZY, Tsumagari K and Kandil E: Immunohistochemistry as a reliable method for detection of BRAF-V600E mutation in melanoma: A systematic review and meta-analysis of current published literature. J Surg Res 203: 407-415, 2016 